\title{
Shear wave splitting across the Iceland hot spot: Results from the ICEMELT experiment
}

\author{
Ingi T. Bjarnason, ${ }^{1}$ Paul G. Silver, ${ }^{2}$ Georg Rümpker, ${ }^{3}$ and Sean C. Solomon ${ }^{2}$ \\ Received 1 August 2001; revised 7 June 2002; accepted 9 July 2002; published 31 December 2002.
}

[1] We report on observations of upper mantle anisotropy from the splitting of teleseismic shear waves $(S K S, S K K S$, and $P K S)$ recorded by the ICEMELT broadband seismometer network in Iceland. In a ridge-centered hot spot locale, mantle anisotropy may be generated by flow-induced lattice-preferred orientation of olivine grains or the anisotropic distribution of magma. Splitting measurements of teleseismic shear waves may thus provide diagnostic information on upper mantle flow and/or the distribution of retained melt associated with the Iceland mantle plume. In eastern Iceland, fast polarization directions lie between $\mathrm{N} 10^{\circ} \mathrm{W}$ and $\mathrm{N} 45^{\circ} \mathrm{W}$ and average $\mathrm{N} 24^{\circ} \mathrm{W}$; delay times between the fast and slow shear waves are generally $0.7-1.35 \mathrm{~s}$. In western Iceland, in contrast, the fast polarization directions, while less well constrained, yield an average value of $\mathrm{N} 23^{\circ} \mathrm{E}$ and delay times are smaller $(0.2-0.95 \mathrm{~s})$. We propose that splitting in eastern Iceland is caused by a 100 - to 200 -km-thick anisotropic layer in the upper mantle. The observed fast directions in eastern Iceland, however, do not correspond either to the plate spreading direction or to a pattern of radial mantle flow from the center of the Iceland hot spot. We suggest that the relatively uniform direction and magnitude of splitting in eastern Iceland, situated on the Eurasian plate, may therefore reflect the large-scale flow field of the North Atlantic upper mantle. We hypothesize that the different pattern of anisotropy beneath western Iceland, part of the North American plate, is due to the different absolute motions of the two plates. By this view, splitting in eastern and western Iceland is the consequence of shear by North American and Eurasian plate motion relative to the background mantle flow. From absolute plate motion models, in which the Eurasian plate is approximately stationary and the North American plate is moving approximately westward, the splitting observations in both eastern and western Iceland can be satisfied by a background upper mantle flow in the direction $\mathrm{N} 34^{\circ} \mathrm{W}$ and a velocity of $3 \mathrm{~cm} / \mathrm{yr}$ in a hot spot reference frame. This inference can be used to test mantle flow models. In particular, it is inconsistent with kinematic flow models, which predict southward flow, or models where flow is dominated by subduction-related sources of mantle buoyancy, which predict westward flow. Our observations are more compatible with the flow field predicted from global seismic tomography models, which in particular include the influence of the large-scale lower mantle upwelling beneath southern Africa. While the hypothesized association between our observations and this upwelling is presently speculative, it makes a very specific and testable prediction about the flow field and hence anisotropy beneath the rest of the Atlantic basin. INDEX TERMS: 7218 Seismology: Lithosphere and upper mantle; 8120 Tectonophysics: Dynamics of lithosphere and mantle—general; 8155 Tectonophysics: Plate motions - general; KEYWORDS: Iceland, anisotropy, hot spot, plate motion, shear wave splitting, mantle flow

Citation: Bjarnason, I. T., P. G. Silver, G. Rümpker, and S. C. Solomon, Shear wave splitting across the Iceland hot spot: Results from the ICEMELT experiment, J. Geophys. Res., 107(B12), 2382, doi:10.1029/2001JB000916, 2002.

\footnotetext{
${ }^{1}$ Science Institute, University of Iceland, Reykjavík, Iceland.

${ }^{2}$ Department of Terrestrial Magnetism, Carnegie Institution of Washington, Washington, D. C., USA.

${ }^{3}$ GeoForschungsZentrum, Potsdam, Germany.
}

Copyright 2002 by the American Geophysical Union. 0148-0227/02/2001JB000916\$09.00

\section{Introduction}

[2] The interaction between the Iceland plume and MidAtlantic Ridge has several manifestations, but even a basic understanding of the form of upper mantle flow at Iceland has yet to be achieved. The Iceland hot spot generates a broad topographic high [Vogt, 1971], thicker than normal crust [Bjarnason et al., 1993; Staples et al., 1997; Menke 


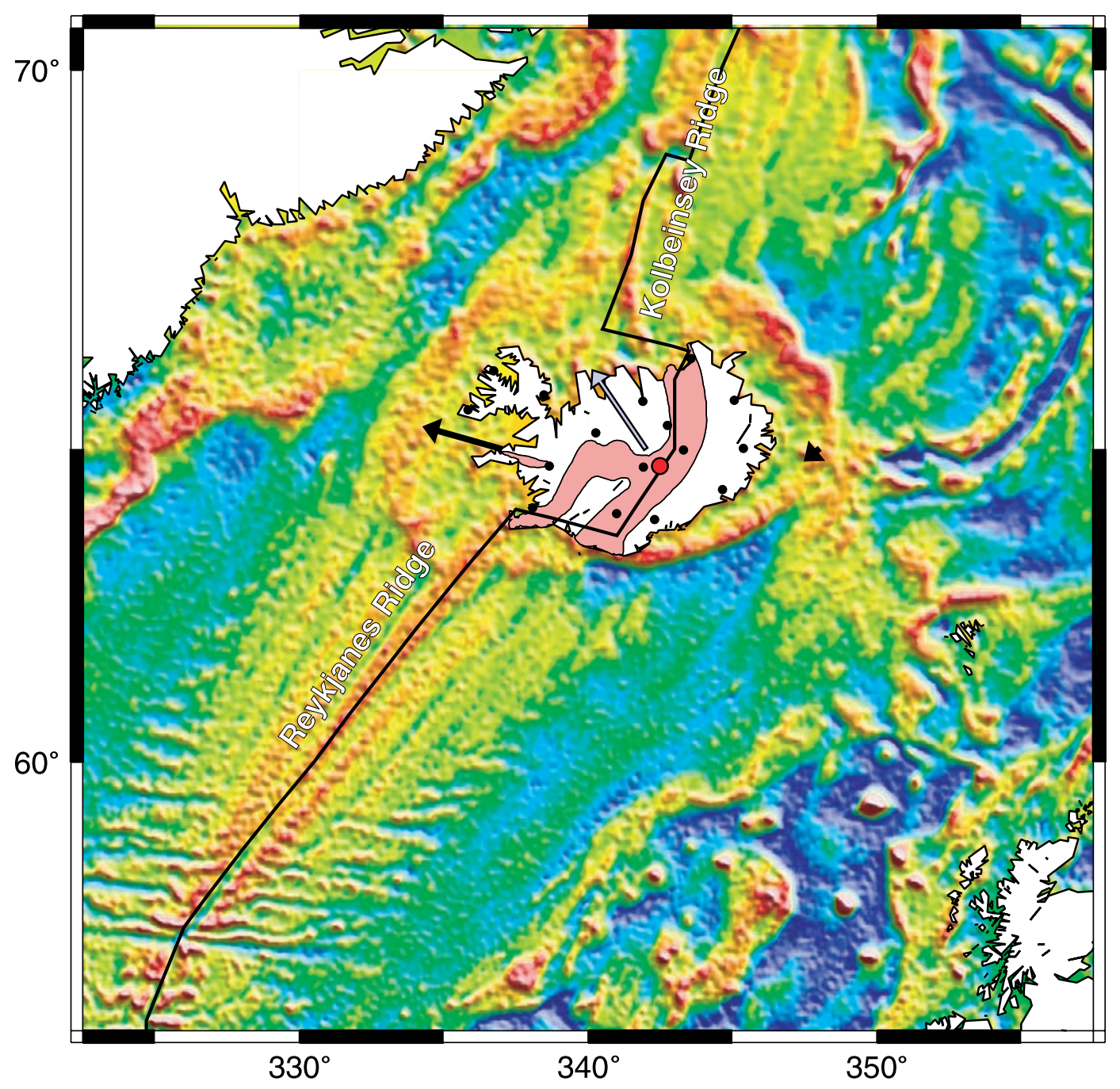

Figure 1. Tectonic environment of Iceland. The black line shows the approximate location of the MidAtlantic Ridge, which passes through Iceland, the red circle indicates the approximate locus of the Iceland plume as inferred from upper mantle seismic tomography [Wolfe et al., 1997], the pink areas on Iceland denote neovolcanic zones, and black arrows give the absolute velocities of the North American and Eurasian plates at Iceland ( 25 and $0.6 \mathrm{~mm} / \mathrm{yr}$, respectively) predicted by the HS2-NUVEL1 plate motion model [Gripp and Gordon, 1990]. Also shown is the inferred mantle flow velocity beneath Iceland of $30 \mathrm{~mm} / \mathrm{yr}$ (gray arrow); see text. Black dots indicate the locations of the broadband seismic stations of the ICEMELT experiment, as well as GSN station BORG and DTM station AKU (cosited with ICEMELT station AKUD; see also Figure 6a). Indication of seafloor topography illustrated by the satellite-derived gravity field of the North Atlantic; yellow-to-red colors indicate more positive gravity values (corresponding to shallower seafloor), while green-to-blue colors indicate more negative values (and deeper seafloor).

et al., 1998; Darbyshire et al., 1998], and a distinctive geochemical anomaly [Schilling, 1973] that extends southward along the Reykjanes Ridge. Neovolcanic zones within Iceland are interpreted as on-land extensions of the ridge. Several kinematic and geodynamic models have been invoked to explain these characteristics [Vogt, 1971; Schilling, 1991; Ribe et al., 1995; White et al., 1995; Ito et al., 1996, 1999], but further observations are needed to test them. ICEMELT was a regional broadband seismic experiment, operated by the Department of Terrestrial Magnetism (DTM) of the Carnegie Institution of Washington and the Science Institute of the University of
Iceland, designed to determine the detailed upper mantle structure beneath a mid-ocean ridge hot spot (Figure 1) and thus provide critical information for constraining mantle dynamics at Iceland.

[3] In this study we report on the pattern of upper mantle anisotropy implied by the splitting of teleseismic shear phases recorded by the ICEMELT network, and we discuss the implications for mantle flow beneath Iceland. The anisotropy measured by splitting of $S K S$ phases provides constraints on the geometry of both upper mantle flow and mantle melting beneath this ridge-centered hot spot. Because olivine, the most abundant mineral in the upper 
mantle, is anisotropic and develops lattice-preferred orientation in response to strain, splitting across Iceland may reflect the flow-induced alignment of the olivine $a$ [100] axes [e.g., Francis, 1969; Christensen, 1984; Blackman et al., 1996]. The presence of melt in vertically aligned cracks can also produce splitting [Kendall, 1994; Blackman and Kendall, 1997], although a random distribution of melt in cracks or tubules would yield an isotropic bulk structure. While measurements of surface wave azimuthal anisotropy [Nishimura and Forsyth, 1988; Montagner and Tanimoto, 1990, 1991], studies of $P_{n}$ anisotropy [Raitt et al., 1969], and a local study of shear wave splitting [Wolfe and Solomon, 1998] all provide strong evidence that olivine $a$ axes align parallel to the spreading direction at fast spreading ridges such as the East Pacific Rise, the pattern of surface wave azimuthal anisotropy appears more complex at slow spreading ridges such as the Mid-Atlantic Ridge at Iceland [Montagner and Tanimoto, 1990, 1991; Silveira et al., 1998]. In particular, it is unknown whether the anisotropy at Iceland reflects mantle flow fields dominated by cylindrical upwelling and radial divergence beneath the Iceland hot spot [e.g., Ito et al., 1999], ridge-related linear upwelling and bilateral divergence [Francis, 1969; Blackman et al., 1996], asthenospheric shear due to absolute plate motion [Vinnik et al., 1989], or the larger-scale background pattern of upper mantle flow [Hager and O'Connell, 1979; Chase, 1979; Parmentier and Oliver, 1979; Lithgow-Bertelloni and Richards, 1998].

[4] The ICEMELT portable network consisted of 15 broadband, three-component STS-2 seismometers distributed throughout Iceland [Bjarnason et al., 1996] (Figure 1). The network was installed in stages during a two-year period from 1993-1995 and recorded data until the autumn of 1996. In addition to these portable stations, we also use data from two permanent stations: the Global Seismograph Network (GSN) station BORG, installed in 1994, and the DTM broadband station AKU, in operation since 1972 [Evans and Sacks, 1979]. The ICEMELT network provided excellent coverage of the different tectonic regions in Iceland. For instance, stations HNJO, MDAL, KLU, ASBS, HOFF, and BIRH were located on older Icelandic crust and sampled off-axis regions on the North American and Eurasian plates. Stations LJOP, ASKJ, and BRE were sited at the currently active plate boundary in the Northern and Eastern Volcanic Zones. The central station NYD was sited above the locus of the Iceland hot spot as imaged by seismic tomography [Wolfe et al., 1997]. ICEMELT data have been previously used to identify the isotropic characteristics of mantle seismic structure beneath Iceland. Body wave tomography constrains the temperature and width of the upper mantle portion of the Iceland plume [Bjarnason et al., 1996; Wolfe et al., 1997], and measurements of the transition zone thickness beneath Iceland suggest that the Iceland plume arises from the lower mantle [Shen et al., 1996, 1998]. The measurements of anisotropy reported here complement these earlier studies.

\section{Shear Wave Splitting Analysis}

[5] A shear wave passing through a homogeneous, anisotropic layer splits into two waves with orthogonal polarizations and different wave speeds. Measurements of shear wave splitting yield the direction of polarization $\phi$ of the fast shear wave and the delay time $\delta t$ between fast and slow shear waves. Splitting parameters obtained from $S K S$, $S K K S$, and $P K S$ core phases reflect the path-integrated effects of upper mantle anisotropy beneath the receiving seismometer [Silver, 1996; Savage, 1999] and provide information on the orientation of the anisotropy as well as the combined effects of the thickness of the anisotropic region and the degree of anisotropy [Silver and Chan, 1988, 1991].

[6] At islands such as Iceland, the high level of oceanic wave-related seismic noise [Wilcock et al., 1999] inevitably degrades the quality of waveforms recorded on broadband arrays, and most $S K S$ phases are unusable unless low-pass filtered at periods greater than $\sim 10 \mathrm{~s}$. Individual measurements of the splitting delay time and fast shear direction thus contain large errors. Figure 2 shows an example of an individual splitting measurement made using the method of Silver and Chan [1991] at the ICEMELT station ASBS. While there is a clear splitting signal in the data (Figures $2 \mathrm{~b}$ and $2 \mathrm{c}$ ), the $95 \%$ confidence region shown in Figure $2 \mathrm{~d}$ is not well constrained. We therefore apply the modification of Wolfe and Silver [1998], a procedure by which a single set of splitting parameters is obtained by stacking misfit surfaces from multiple earthquakes, such as displayed in Figure 2d. The solution after stacking 13 misfit surfaces at ASBS, shown in Figure 3, indicates that errors are reduced and the solution is better constrained than for individual events. Examples of splitting solutions after stacking at KLU and REYV are shown in Figures 4 and 5 . In contrast to the $1.2 \mathrm{~s}$ delay time at ASBS, splitting at $\mathrm{KLU}$ is small in magnitude $(\delta t=0.65 \mathrm{~s})$ and splitting at REYV is negligible.

[7] The splitting parameters for the ICEMELT network derived by the stacking procedure of Wolfe and Silver [1998] are given in Table 1 (see the electronic supplement for detailed information about the data $\mathrm{set}^{1}$ ). Each stacked solution is based on at least 9 and as many as 15 phases having the best signal-to-noise ratio recorded during the experiment. We find no indication of a variation of splitting parameters with earthquake back azimuth, as might be produced by the presence of two homogenous anisotropic layers having different directions of fast polarization [Silver and Savage, 1994], a dipping symmetry axis, or lateral heterogeneity [Rümpker and Ryberg, 2000].

\section{Splitting Results}

[8] The splitting parameters observed across Iceland (Figure 6a) can be divided into two groups. The eastern half of Iceland displays generally strong anisotropy, with delay times $\delta t$ of $0.7-1.35 \mathrm{~s}$ and fast polarization directions $\phi$ (measured clockwise from north) between about $-10^{\circ}$ and $-45^{\circ}$. In contrast, the western half of Iceland displays weaker anisotropy, with $\delta t=0.2-0.95 \mathrm{~s}$ and $\phi$

\footnotetext{
${ }^{1}$ Supporting data set is available via Web browser or via Anonymous FTP from ftp://agu.org, directory "apend" (Username = "anonymous", Password = "guest"); subdirectories in the ftp site are arranged by paper number. Information on searching and submitting electronic supplements is found at http://www.agu.org/pubs/esupp_about.html.
} 

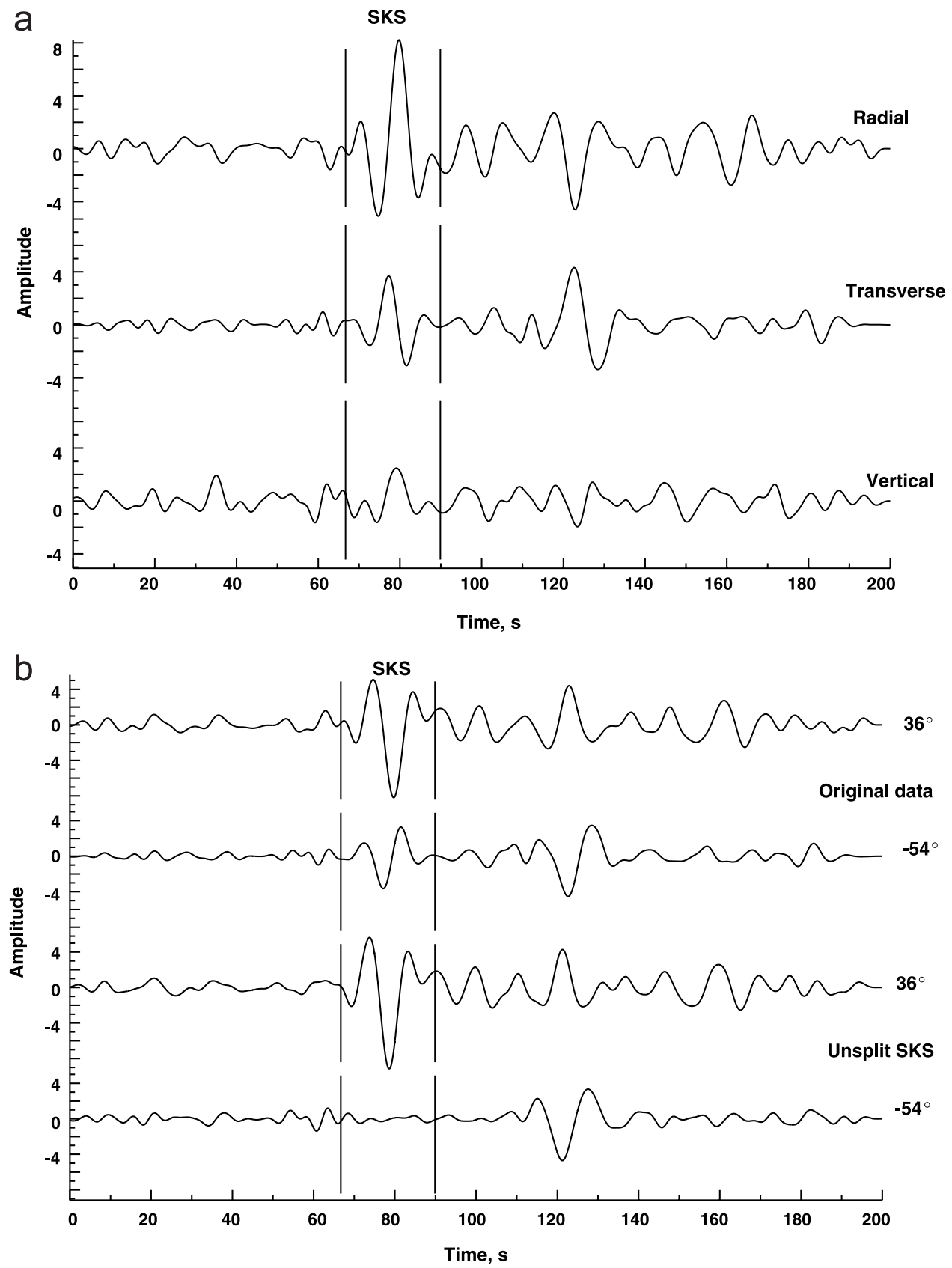

Figure 2. An example of the determination of shear wave splitting from a single event recorded at station ASBS on the eastern coast of Iceland. (a) Three-component seismogram of the SKS phase from the Philippine earthquake of 24 May 1995, located at an epicentral distance of $97^{\circ}$ and a back azimuth of $39^{\circ}$. The scale on the vertical axis and the origin of the time axis are arbitrary. (b) Radial and transverse seismograms before and after correcting for estimated splitting parameters. Correcting for splitting effectively removes energy on the transverse component. (c) (top) Waveforms in the fast and slow frames (solid and dashed lines, respectively) show $\sim 1.5 \mathrm{~s}$ of splitting before correction (left) and after (right). (bottom) Horizontal particle motion (fast and slow components on the horizontal and vertical axes, respectively) is elliptical before (left) and rectilinear after (right) correction for splitting. (d) Contours of confidence regions for splitting parameters; the 1 -contour gives the $95 \%$ confidence interval. The measured splitting is $\phi=-20^{\circ}, \delta t=1.55 \mathrm{~s}$.

ranging from $-4^{\circ}$ to $+30^{\circ}$. These east-west differences are clearly seen in plots of splitting parameters versus longitude (Figures $6 \mathrm{~b}$ and $6 \mathrm{c}$ ). The sole exception to these generalizations is station NYD, which although geograph- ically within the eastern group displays only weak evidence for splitting.

[9] Since crustal contribution to splitting should be small ( $\leq 0.3$ s) [e.g., Menke et al., 1993; Savage, 1999], the 
C

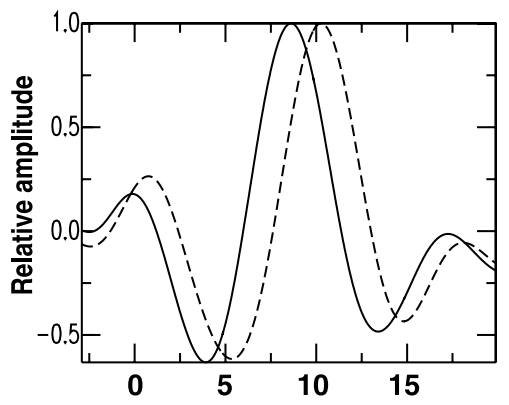

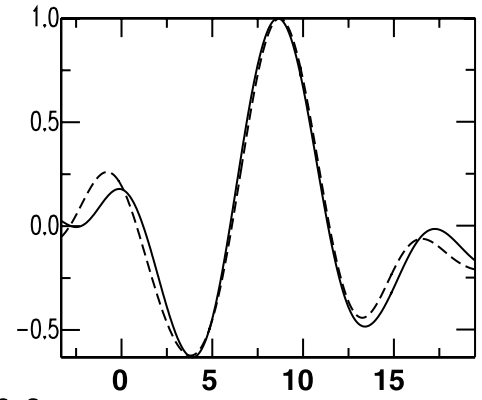

Time, s

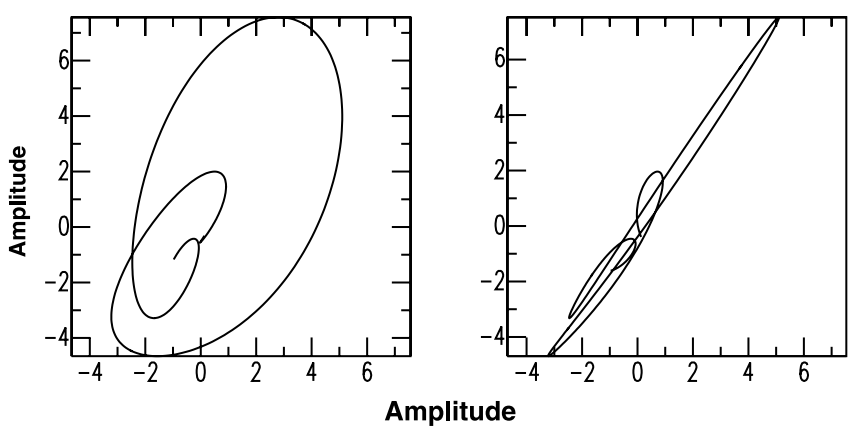

d

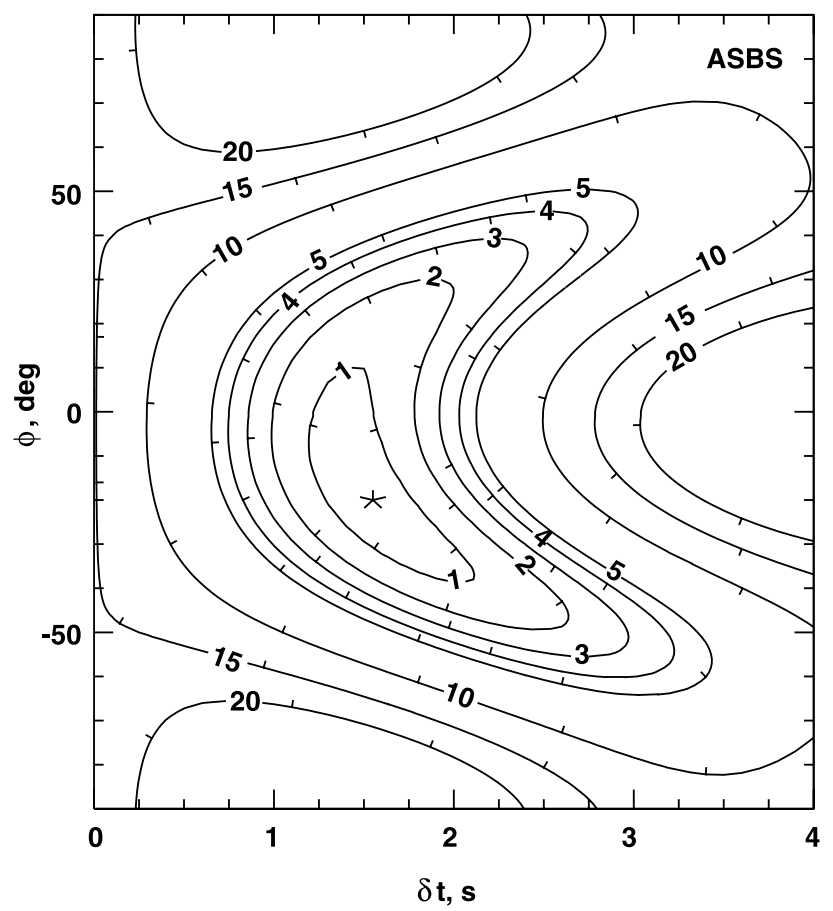

Figure 2. (continued)

measurements in Figure 6 dominantly reflect the anisotropy of the upper mantle beneath the ICEMELT seismic network. Splitting parameters lack vertical resolution and thus do not constrain the depth extent of anisotropy. On the basis of the intrinsic anisotropy observed in naturally occurring peridotites, the thickness of the anisotropic layer may nonetheless be estimated from the delay time. This intrinsic anisotropy has an average value of $\sim 4 \%$ but can range from $\sim 2 \%$ to $8 \%$ [Ben Ismail and Mainprice, 1998]. Using a 4\% figure as representative, every $1 \mathrm{~s}$ of splitting time delay translates to $\sim 100 \mathrm{~km}$ of anisotropic material [Silver, 1996]. The splitting times across eastern Iceland are therefore consistent with an anisotropic layer 100 to $200 \mathrm{~km}$ thick in the uppermost mantle.

\section{Evaluation of Simple Models}

[10] The shear wave splitting results provide information for constraining the form of mantle flow and melting beneath Iceland. There are two potential causes for aniso- 


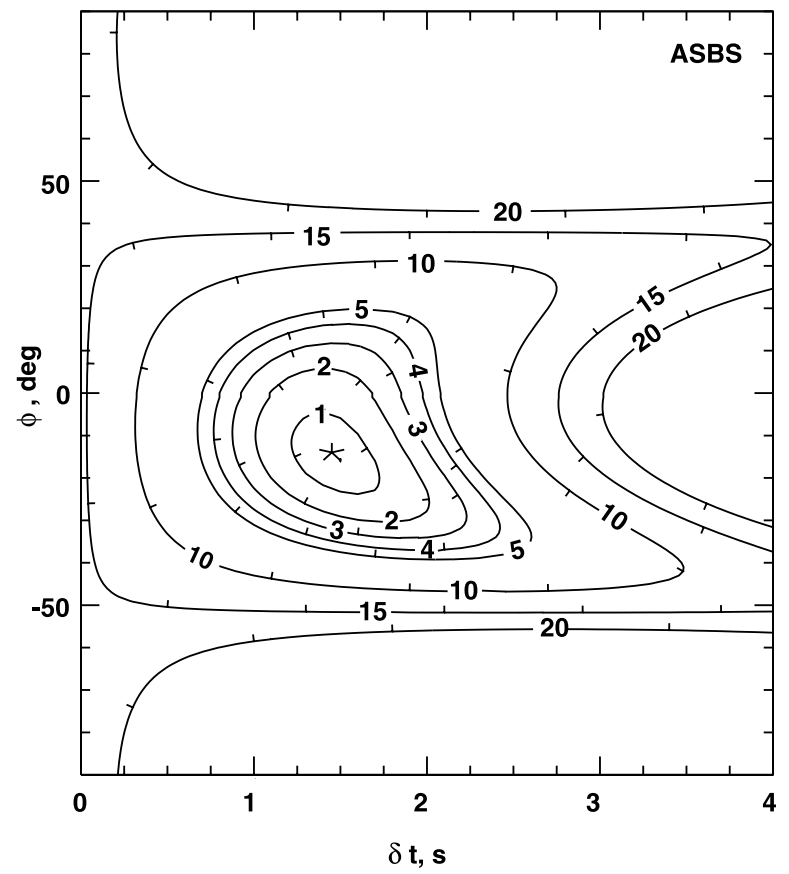

Figure 3. Splitting solution for station ASBS obtained by stacking 13 records: $\phi=-12 \pm 3^{\circ}, \delta t=1.20 \pm 0.10 \mathrm{~s}$.

tropy at Iceland: lattice-preferred orientation (LPO) of anisotropic mantle minerals and shape-preferred orientation (SPO) of oriented inclusions of fluids, such as melt or other materials with contrasting elastic properties. On the basis of observations of mantle-derived rocks, laboratory results,

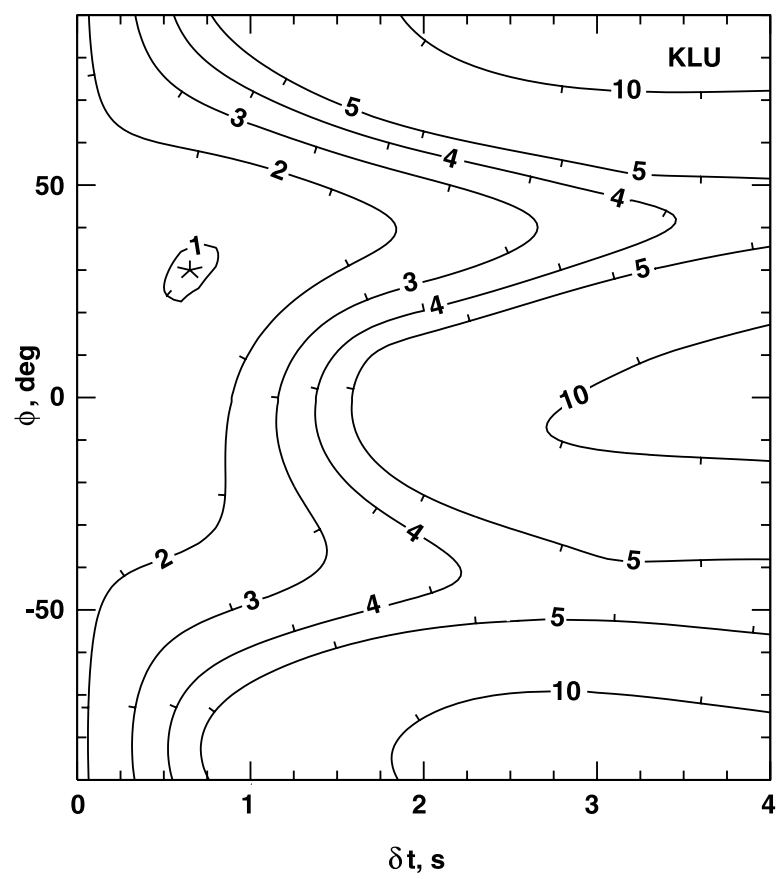

Figure 4. Splitting solution for station KLU in western Iceland obtained by stacking 15 records: $\phi=30 \pm 4^{\circ}, \delta t=$ $0.65 \pm 0.10 \mathrm{~s}$.

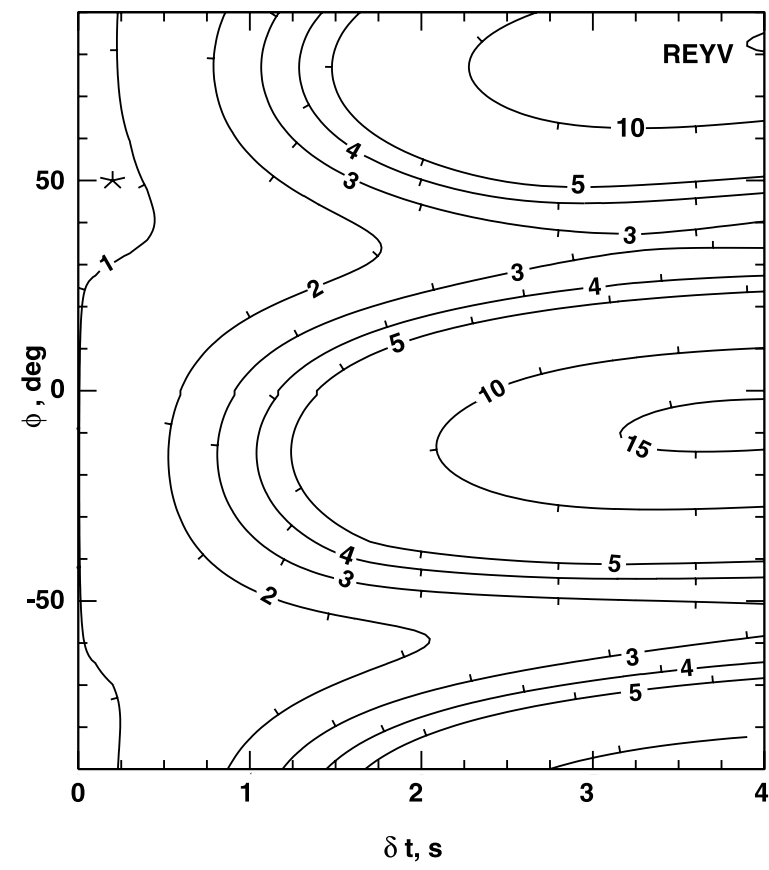

Figure 5. Splitting solution for station REYV showing negligible anisotropy from a stack of 12 stations: $\delta t=0.20 \pm$ $0.20 \mathrm{~s}$.

and seismic measurements of shear wave splitting, the anisotropy of the continental mantle is believed to be dominated by olivine LPO (see Silver [1996] and references therein). At fast spreading ridges, measurements of anisotropy from surface waves [Nishimura and Forsyth, 1988; Montagner and Tanimoto, 1990, 1991] and shear wave splitting [Wolfe and Solomon, 1998] yield fast directions that are parallel to the spreading direction, which has led to the conclusion that the olivine $a$ axes are aligned parallel to this direction as well. However, this pattern of surface wave azimuthal anisotropy breaks down at slow spreading ridges [Montagner and Tanimoto, 1990, 1991; Silveira et al., 1998], and it is thus unclear what the splitting pattern should be at a ridge-centered hot spot such as Iceland.

Table 1. Shear Wave Splitting Parameters for ICEMELT Stations ${ }^{a}$

\begin{tabular}{lrrrrr}
\hline Station & $\phi$ & $\sigma_{\phi}$ & $\delta t, \mathrm{~s}$ & $\sigma_{\delta t}, \mathrm{~s}$ & Phases \\
\hline AKU & $-9^{\circ}$ & $4^{\circ}$ & 0.90 & 0.10 & 13 \\
ASBS & $-12^{\circ}$ & $3^{\circ}$ & 1.20 & 0.10 & 13 \\
ASKJ & $-44^{\circ}$ & $4^{\circ}$ & 0.90 & 0.10 & 11 \\
BIRH & $-19^{\circ}$ & $4^{\circ}$ & 1.05 & 0.15 & 10 \\
BLOL & $18^{\circ}$ & $3^{\circ}$ & 0.95 & 0.15 & 13 \\
BORG & $20^{\circ}$ & $5^{\circ}$ & 0.60 & 0.10 & 14 \\
BRE & $-26^{\circ}$ & $2^{\circ}$ & 1.35 & 0.15 & 14 \\
HNJO & $25^{\circ}$ & $11^{\circ}$ & 0.40 & 0.15 & 10 \\
HOFF & $-27^{\circ}$ & $2^{\circ}$ & 1.05 & 0.05 & 13 \\
KAF & $-40^{\circ}$ & $2^{\circ}$ & 1.00 & 0.15 & 15 \\
KLU & $30^{\circ}$ & $4^{\circ}$ & 0.65 & 0.10 & 15 \\
LJOP & $-41^{\circ}$ & $3^{\circ}$ & 0.70 & 0.15 & 9 \\
MDAL & $-4^{\circ}$ & $2^{\circ}$ & 0.85 & 0.10 & 9 \\
NYD & $22^{\circ}$ & $11^{\circ}$ & 0.40 & 0.15 & 10 \\
REYV & $50^{\circ}$ & $25^{\circ}$ & 0.20 & 0.20 & 12 \\
SKOT & $-23^{\circ}$ & $4^{\circ}$ & 0.70 & 0.10 & 12 \\
\hline
\end{tabular}

${ }^{\mathrm{a}}$ The $\sigma_{\phi}$ and $\sigma_{\delta t}$ are the standard deviations in $\phi$ and $\delta t$, respectively, given by the stacking method of Wolfe and Silver [1998]. 

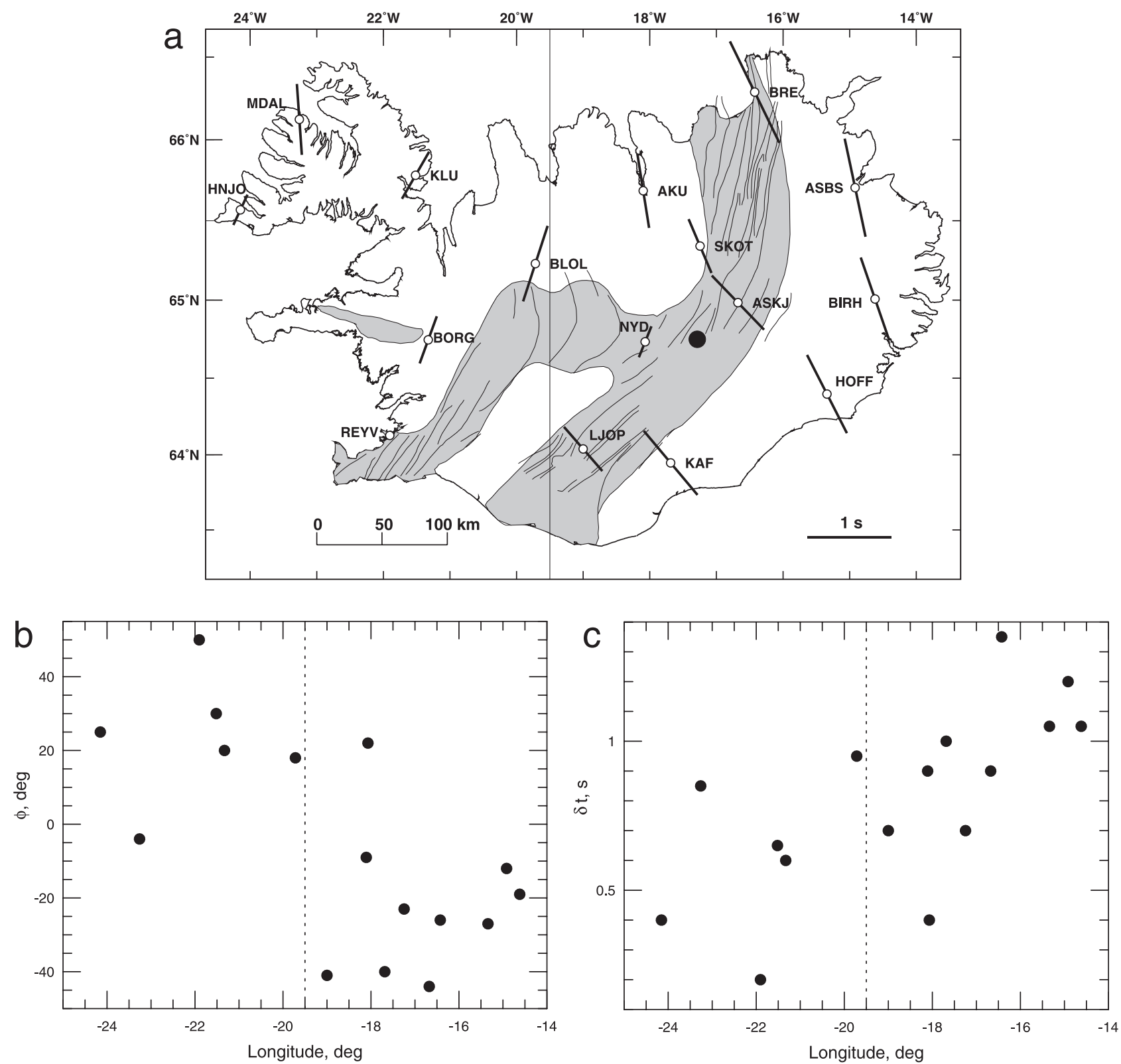

Figure 6. (a) Splitting results in map view. At each station the symbol orientation gives the fast polarization direction $\phi$, and the symbol length is linearly proportional to $\delta t$ (see legend). Also indicated are principal faults of the neovolcanic zones (grey). Two major differences between eastern and western Iceland are seen in the data: (b) $\phi$ varies from about $+20^{\circ}$ in the west to $-20^{\circ}$ in the east, and (c) $\delta t$ varies from $\sim 0.6 \mathrm{~s}$ in the west to $\sim 1.0 \mathrm{~s}$ in the east.

[11] There are six potential contributions to mantle anisotropy beneath Iceland (Figure 7). The single SPO-related contribution is that induced by ridge-parallel, melt-filled cracks. We expect there to be five potential contributions to the flow field beneath Iceland and therefore five contributions to strain-induced LPO anisotropy. These are flow associated with the ridge upwelling and spreading process [Francis, 1969; Blackman et al., 1996], flow associated with absolute plate motion [Vinnik et al., 1989], ridgecentered, hot spot-related flow [Ribe et al., 1995; Ito et al., 1996, 1999], flow along the Reykjanes Ridge [Vogt, 1971; Schilling, 1973; White et al., 1995], and regional or background flow of the upper mantle [Hager and O'Con- nell, 1979; Chase, 1979; Parmentier and Oliver, 1979; Lithgow-Bertelloni and Richards, 1998]. All but the last of these models has a well-defined flow direction. We make a prediction of the splitting parameters for idealized versions of each of these six models, assuming for the LPOrelated cases that the $a$ axes of mantle olivine grains are contained within the flow plane and parallel to the flow line, an alignment believed to be the dominant form of anisotropy at large strains [Zhang and Karato, 1995]. We further assume that for near-vertical propagation of shear waves (as with the core phases of this study) and for a nearly horizontal preferred orientation of the olivine $a$ axes, $\phi$ will be parallel to the horizontal projection of the $a$ axes. For the 
a)

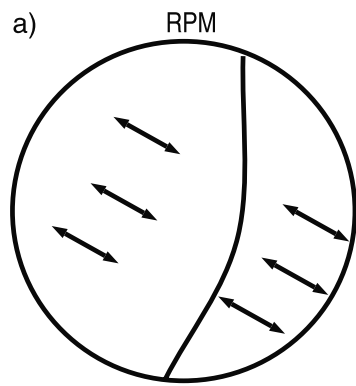

c)

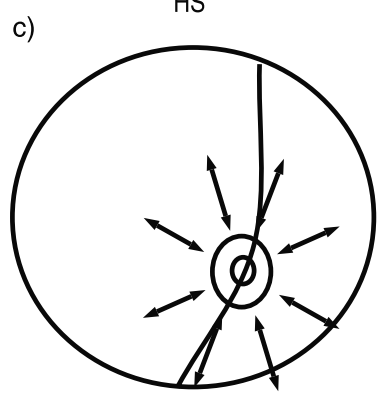

e)

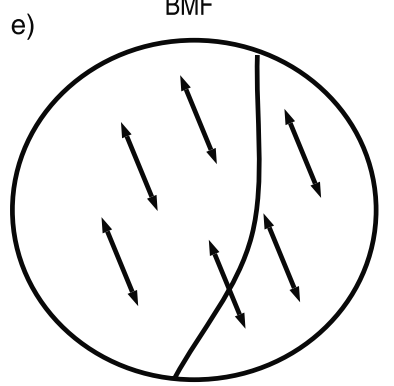

b)
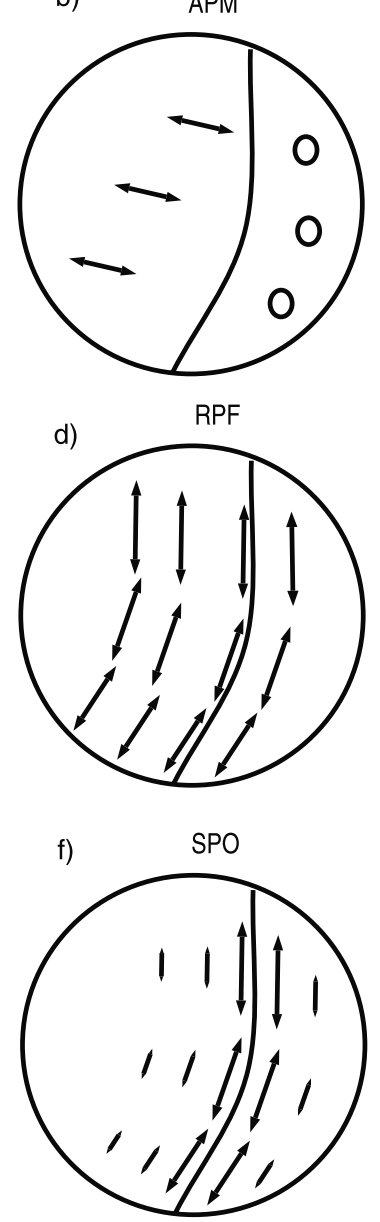

Figure 7. Schematic depiction of possible causes of splitting beneath Iceland and the predicted values of $\phi$. It is assumed that $\phi$ follows the flow line where mantle flow is horizontal. (a) Relative plate motion (RPM). Mantle flow is assumed to be parallel to transform faults. (b) Flow aligned by absolute plate motion (APM). The APM direction is from HS2-NUVEL1 [Gripp and Gordon, 1990]. For the Eurasian plate, the flow direction is unconstrained because the plate is moving slowly. We take the contribution to anisotropy to be negligible on the eastern side of Iceland. (c) Hot spot (HS) flow. Mantle flow is assumed to be radial outward from the inferred location of the hot spot. There will be a central region where flow is vertical and negligible splitting is expected. (d) Ridge-parallel flow (RPF). Mantle flow is assumed to be southward from the Icelandic neovolcanic zones toward the Reykjanes Ridge. The model is motivated by topographic and geochemical evidence for southward flow along this ridge system [Vogt, 1971; Schilling, 1973; White et al., 1995]. (e) Background mantle flow (BMF). Anisotropy is assumed to be dominated by general mantle circulation unrelated to surface plate processes. The direction is unconstrained, but it should be coherent throughout Iceland. (f) Shape-preferred orientation (SPO). This anisotropy is not produced by flow-induced LPO but by preferentially oriented, vertical to steeply dipping, melt-filled cracks [Blackman and Kendall, 1997]. Such cracks are assumed to strike parallel to the ridge.

same propagation paths, splitting should be negligible where the $a$ axes are nearly vertical [Silver, 1996].

[12] The predicted splitting pattern for each of these models is as follows:

1. In the spreading model (Figure 7a) for anisotropy associated with the spreading process, flow is generally in the direction of relative plate motion (RPM), i.e., parallel to the orientation of transform faults. Along the neovolcanic zone, the $a$ axes are nearly vertical and splitting should be weak. Away from the neovolcanic zone, the olivine $a$ axes should be aligned with the spreading direction, and $\phi$ should likewise indicate this direction.

2. In the absolute plate motion model (Figure 7b) for flow associated with absolute plate motion (APM), we assume that simple asthenospheric flow develops beneath the plate [Silver, 1996], with a horizontal flow plane and a flow line parallel to the APM direction. The direction $\phi$ should be parallel to APM. Because Iceland is centered on the boundary of the North American and Eurasian plates, the APM direction changes between eastern and western Iceland. For the North American plate in western Iceland, the APM is in a westerly direction [Gripp and Gordon, 1990]. For the Eurasian plate in eastern Iceland, the direction is poorly constrained because the plate velocity is not significantly different from zero. We thus expect negligible APM splitting on the Eurasian side.

3. In the hot spot model (Figure 7c), hot spot (HS) flow is assumed to be vertical at the center of the plume conduit and to diverge radially from the plume axis at the base of the lithosphere. At the plume axis, the olivine $a$ axes are vertical and splitting of teleseismic shear waves should be weak. Away from the axis, the $a$ axes should be subhorizontal and directed radially outward from the plume axis. The direction $\phi$ of fast shear waves should also be radial [Rümpker and Silver, 2000]. This particular pattern is strictly for a plume rising beneath a stationary plate; there may be distortions of this pattern due to plate motion [e.g., Sleep, 1990; Savage and Sheehan, 2000]. Because Iceland is a ridge-centered hot spot, there will be some alteration of this radial pattern due to spreading, although it should be relatively minor for such a slow spreading ridge [Ito et al., 1996; N. M. Ribe personal communication, 2002].

4. In the ridge-parallel flow (RPF) model (Figure 7d), for persistent mantle flow along the ridge, $\phi$ should indicate a direction oriented parallel to the ridge throughout Iceland.

5. In the background mantle flow (BMF) model (Figure $7 \mathrm{e})$, the background flow field is expected to vary slowly over the Iceland region, although its direction is unknown. By the same argument, the contribution of this mechanism to $\phi$ is also unknown, but its effect should be homogeneous throughout Iceland. This explanation for the origin of splitting in Iceland was offered earlier [Bjarnason et al., 1996], when there were fewer observations and a uniform direction for fast shear waves was consistent with the data then available.

6. In the melt anisotropy model (Figure 7f), if melt is present in vertical or steeply dipping cracks aligned parallel to the ridge (perpendicular to the direction of least principal stress), then the direction $\phi$ for this SPO mechanism should be parallel to the strike of ridge-related faulting in the neovolcanic zone. If melt were the dominant influence, the 
largest splitting values would be found beneath stations in the neovolcanic zone, and $\delta t$ would decrease with distance from this region as the fraction of melt diminishes.

[13] On the basis of comparisons of our observations to the patterns expected of each of these simple models, we conclude that there is no good match to any of the models. Although splitting at station NYD is small, as expected under the hot spot splitting model for a site centered over the upper mantle plume anomaly imaged tomographically [Wolfe et al., 1997], there is no sign of the radial pattern predicted by this model away from the axis of the plume conduit. There is also no sign of a generally symmetric pattern of ridge-normal directions for fast shear waves, as would be expected from spreading processes. Two stations, ASKJ and LJOP, show fast shear directions perpendicular to the local strike of the spreading boundary, but these stations lie within the neovolcanic zone (where splitting is predicted to be weak from this mechanism) and their fast polarization directions are not very different from those of other stations in eastern Iceland. There is a suggestion of a ridge-parallel component for the western stations, although the delay times are small. There is no obvious APM component in western Iceland. The observed average direction for fast shear waves on the western side is $+23^{\circ}$ ( or $-157^{\circ}$ ), nearly orthogonal to the predicted direction for APM [Gripp and Gordon, 1990]. If background mantle flow were dominant, we would expect a coherent pattern over all of Iceland, whereas we see two distinct patterns on the two sides of the island. Finally, the observations do not match the predictions for ridge-aligned, vertical to steeply dipping, meltfilled cracks. This last result is consistent with splitting measurements from the MELT experiment at the East Pacific Rise, which yielded no evidence for such meltinduced anisotropy, because the dominant trend for splitting parameters is parallel to spreading both on- and off-axis [Wolfe and Solomon, 1998]. It thus appears that no single process in Figure 7 dominates the splitting signal and that more complex models need to be considered.

\section{Modified APM Model}

[14] We next consider a modified APM model, in which the North American and Eurasian plates are moving not with respect to a stationary mantle, but rather to a mantle flowing at a uniform horizontal vector velocity, $V_{m}$, in the north Atlantic region. We assume that $V_{m}$ represents a rigid translation of the subasthenospheric mantle, so that the anisotropy thus developed is restricted to the asthenosphere. As discussed by Silver and Holt [2002], the direction of asthenospheric shear will then be parallel to the vectorial difference between the absolute plate velocity vector, $V_{p}$, and $V_{m}$. The values of $\phi$ thus denote directions parallel (or antiparallel) to the orientation of $V_{p}-V_{m}$.

[15] We assume further that the APM velocities (azimuth, magnitude) of the North American $\left(-74^{\circ}, 25 \mathrm{~mm} / \mathrm{yr}\right)$ and Eurasian $\left(-129^{\circ}, 5.6 \mathrm{~mm} / \mathrm{yr}\right)$ plates at Iceland are those given by the hot spot reference frame of plate motion model HS2-NUVEL1 [Gripp and Gordon, 1990]. We take $V_{p}-V_{m}$ for the North American and Eurasian plates to be parallel to the average directions of fast shear wave propagation in western and eastern Iceland, respectively. These averages are $\phi_{W}=+23^{\circ}$ and $\phi_{E}=-24^{\circ}$. It is then possible to solve for
MODIFIED APM
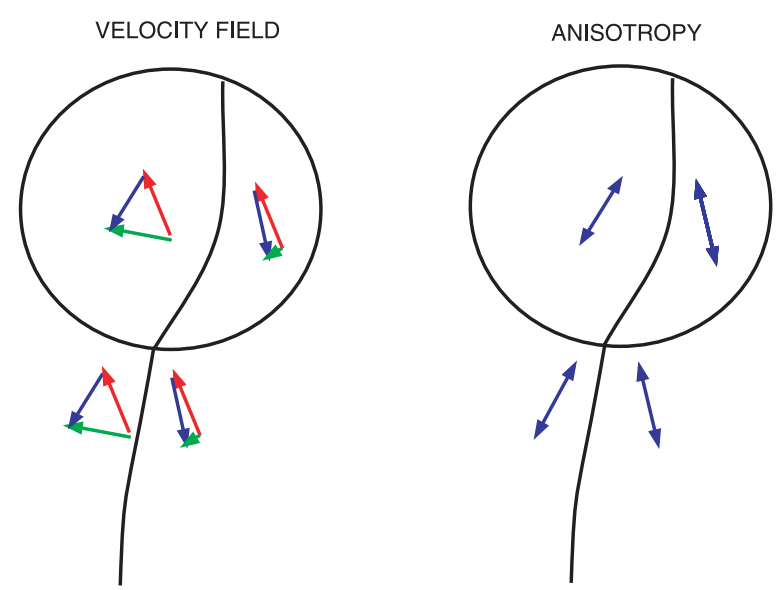

Figure 8. A modified APM model for splitting beneath Iceland. Anisotropy is produced by differential velocity of the surface plates and a non-zero subasthenospheric mantle flow velocity. At left are the velocity fields. Green arrows indicate the velocities $V_{p}$ of the North American and Eurasian plates in a hot spot reference frame, red arrows indicate the subasthenospheric mantle velocity $V_{m}$, and blue arrows give the difference vector. At right are the resulting fast polarization directions $\phi$ for shear wave splitting. The calculated mantle velocity that satisfies both the surface plate velocities and observed values of $\phi$ is $\sim 30 \mathrm{~mm} / \mathrm{yr}$ in the direction $\mathrm{N} 34^{\circ} \mathrm{W}$.

the vector $V_{m}$ uniquely in the same reference frame by simple vector addition (Figure 8), using the methodology of Silver and Holt [2002]. We find that $V_{m}$ has an azimuth and magnitude of $-34^{\circ}$ and $30 \mathrm{~mm} / \mathrm{yr}$, respectively, in the hot spot reference frame.

[16] It is worth noting that the approximate boundary between western and eastern Iceland as indicated by the splitting observations (Figure 6) lies up to $100 \mathrm{~km}$ west of the Northern and Eastern Neovolcanic Zones thought to mark the locus of the present plate boundary in central Iceland. This difference in boundaries may reflect the eastward migration of the boundary between the North American and Eurasian plates in Iceland over the last several million years [Pálmason and Saemundsson, 1974; Óskarsson et al., 1985]. Inasmuch as substantial finite strain is required to alter the LPO fabric in mantle material, the boundary between volumes of mantle displaying the splitting signatures of two plates adjoined at an eastward stepping plate margin should lie to the west of the current plate boundary, as is observed.

\section{Discussion}

\subsection{Possible Effects of Lithospheric Anisotropy}

[17] The above analysis has been based on the simplifying assumption that upper mantle anisotropy arises from a single homogeneous asthenospheric layer. In general, there could instead be two or more layers, or a more complex form of vertical heterogeneity, which would complicate the interpretation. The most likely type of vertical heterogeneity is in the form of distinct contributions from the lithosphere 
and asthenosphere. Each of the models in Figures 7 and 8 is based implicitly on the assumption of negligible contribution from the lithosphere. We use the methods of Silver and Savage [1994] and Rümpker and Silver [1998] to assess the effect of a possible lithospheric contribution to splitting.

[18] As a first approximation, we fix the anisotropy in the lithosphere and solve for anisotropy in the asthenospheric mantle. Surface wave dispersion data indicate that the Icelandic lithosphere far from the neovolcanic zones is $\sim 75 \mathrm{~km}$ thick [Bjarnason, 1999]. We assume that anisotropy within the lithosphere can be described by a simple two-layer model (35-km-thick crust, 40-km-thick mantle). The top crustal layer is assumed to be dominated by crackinduced anisotropy, where the fast-axis $\phi_{L C}$ is parallel to the strike of the Iceland neovolcanic zones and $\delta t_{L C}=0.2 \mathrm{~s}$ [Menke et al., 1993]. In the lithosphere beneath the crust, mantle flow results in a fast-axis $\phi_{L M}$ perpendicular to the strike of the ridge. If the intrinsic anisotropy in the mantle is $4 \%$, the mantle delay time is estimated to be $\delta t_{L M}=0.35 \mathrm{~s}$. Because the fast directions for the two layers are orthogonal, this two-layer model can be described as a single anisotropic layer with $\phi_{L}=\phi_{L M}$ and $\delta t_{L}=\delta t_{L M}-\delta t_{L C}$. The overall effect of the lithospheric anisotropy on the splitting is thus predicted to be small, since $\delta t_{L}$ is only $0.15 \mathrm{~s}$, a value that is less than $25 \%$ of the observed delay times. Nevertheless, for such a lithospheric model, we may solve for an asthenospheric component and compare this estimate to the observed values. Splitting parameters $\phi_{A}$ and $\delta t_{A}$ for the asthenosphere can be determined by a grid search under the constraint that the two-layer apparent splitting parameters closely match the averages determined from the observations (Figure 6). These averages are $\phi_{W}=23^{\circ}$ and $\delta t_{W}=$ $0.60 \mathrm{~s}$ for the western stations and $\phi_{E}=-24^{\circ}$ and $\delta t_{E}=1.0 \mathrm{~s}$ for the eastern stations. Because there is a frequency dependence to apparent splitting for multiple layers, we fix the frequency at $0.1 \mathrm{~Hz}$ to correspond to the central frequency of the ICEMELT $S K S$ data. Some two-layer models generate strong $\pi / 2$-periodic variations of apparent splitting parameters as a function of back azimuth. Because such variations are not evident in the ICEMELT observations, we search for values of $\phi_{A}$ and $\delta t_{A}$ that result in minimal variations with back azimuth.

[19] The strike of the neovolcanic zones across Iceland varies from approximately $\mathrm{N} 15^{\circ} \mathrm{E}$ in the north to $\mathrm{N} 45^{\circ} \mathrm{E}$ in the south. We therefore consider two cases: (1) $\phi_{L}=105^{\circ}$ and (2) $\phi_{L}=135^{\circ}$, both cases with $\delta t_{L}=0.15 \mathrm{~s}$. For the west, using $\phi_{W}=23^{\circ}$ and $\delta t_{W}=0.60 \mathrm{~s}$ as a reference, a grid search yields (1) $\phi_{A}=19^{\circ}$ and $\delta t_{A}=0.75 \mathrm{~s}$ and (2) $\phi_{A}=32^{\circ}$ and $\delta t_{A}$ $=0.70 \mathrm{~s}$. Anisotropy in the lithosphere thus leads to a reduction in apparent delay time by less than $0.2 \mathrm{~s}$ and a change in the fast shear wave direction by not more than $12^{\circ}$. A similar analysis for eastern Iceland, using $\phi_{E}=-24^{\circ}$ and $\delta t_{E}=1.0 \mathrm{~s}$ as a reference, yields (1) $\phi_{A}=-19^{\circ}$ and $\delta t_{A}=$ $1.10 \mathrm{~s}$ and (2) $\phi_{A}=-19^{\circ}$ and $\delta t_{A}=0.90 \mathrm{~s}$. The apparent delay time is affected by $0.1 \mathrm{~s}$ or less and the direction of fast shear waves by $<10^{\circ}$.

[20] On the basis of the above analysis, we conclude that the most likely source of vertical heterogeneity, the presence of an anisotropic lithosphere, is expected to have only a minor effect on the inferred splitting parameters of anisotropy within the underlying asthenosphere. The observed values may thus be interpreted as reflecting this deeper component of anisotropy with little error.

\subsection{Tests and Consequences of the Modified APM Model}

[21] The modified APM model of Figure 8 makes specific predictions for mantle anisotropic properties away from Iceland. In particular, because the model is unrelated to the presence of a plume, it predicts the same pattern of anisotropy to the west and east of the northern Mid-Atlantic Ridge that is found in western and eastern Iceland, respectively. There are limited data on the anisotropy of the North Atlantic mantle with which to compare the Iceland observations. Kuo et al. [1987] examined the differential travel times of paired $S S$ and $S$ waves for which the surface reflection point of the $S S$ phase fell in the North Atlantic $\left(15^{\circ}-50^{\circ} \mathrm{N}\right.$ latitude). The distribution of differential time versus path azimuth they obtained suggested a region-wide pattern of anisotropy in which the olivine $a$ axes are oriented approximately $13^{\circ} /-167^{\circ}$. Two later examinations of larger data sets of $S S-S$ differential times having $S S$ reflection points distributed over larger areas in the North Atlantic [Woodward and Masters, 1991; Sheehan and Solomon, 1991], however, failed to corroborate this result, possibly because the anisotropy pattern varies significantly over such a large region. Observations of $S S$ and $S$ particle motions for three paths with $S S$ reflection points in the North Atlantic $\left(35^{\circ}-50^{\circ} \mathrm{N}\right)$ led Yang and Fischer [1994] to infer fast mantle shear directions of $18^{\circ} /-162^{\circ}, 24^{\circ} /-156^{\circ}$, and $28^{\circ} /-152^{\circ}$ near SS reflection points on the North American and Eurasian plates and at the ridge axis, respectively. These observations have large uncertainties, however, because of poorly constrained contributions from source and receiver regions and because splitting operators for different portions of the $S$ and $S S$ wave paths do not commute [Wolfe and Silver, 1998]. Inversions of surface wave phase velocities for azimuthally anisotropic Earth models yield fast directions generally parallel to absolute plate motions in the oceans [Montagner and Tanimoto, 1990, 1991]. However, a regional study of the North Atlantic [Silveira et al., 1998] yielded instead an approximately north-south fast direction, although the model has good resolution only to the south of Iceland. Finally, Shen et al. [2002] showed that the area of anomalously thin transition zone beneath Iceland, attributed to the effect of elevated temperatures within the Iceland plume, lies at least $100 \mathrm{~km}$ southward of the upper mantle low-velocity zone imaged by body wave tomography [Wolfe et al., 1997]. One explanation for this tilt is northward upper mantle flow at a velocity compatible with our estimate of $3 \mathrm{~cm} / \mathrm{yr}$. We conclude that the limited independent seismic data on the pattern of anisotropy of the North Atlantic upper mantle are not inconsistent with the model of Figure 8 , but additional data are needed to test the generality of the model more thoroughly.

[22] An inference on mantle flow velocity beneath this part of the North Atlantic provides a particularly strong constraint on models for three-dimensional convective flow in the mantle, because the most commonly assumed candidate driving forces for mantle flow predict distinct flow directions in this region. For instance, kinematic models, in which the motions and geometries of the plates are imposed 
as boundary conditions, involve an upper region of flow dominated by plate shear and a lower region dominated by return flow [e.g., Hager and O'Connell, 1979; Chase, 1979; Parmentier and Oliver, 1979]. The return flow beneath Iceland in such models is southward. If the return flow is shallow [e.g., Chase, 1979], $V_{m}$ is predicted to be southward. If the return flow is deep [e.g., Hager and O'Connell, 1979], then $V_{m}$ should be approximately zero in a hot spot reference frame. Neither of these cases provides an adequate explanation for our observations.

[23] Another potentially significant driving force for the mantle flow field is mantle buoyancy heterogeneity. A widely used methodology for predicting this flow field is through instantaneous flow calculations for a specified density heterogeneity model and viscosity profile [Hager and Clayton, 1989; Ricard et al., 1993; Lithgow-Bertelloni and Richards, 1998]. Two types of density models are commonly used, one based on the history of subduction, [e.g., Lithgow-Bertelloni and Richards, 1998], the other inferred from global seismic tomography models. The latter type, while they include the contributions of subducted slabs, also include regions of low seismic velocity that are equated with large-scale upwelling. Differences in the predictions from these two density fields thus provide, in principle, a means for evaluating the relative importance of subduction and upwelling in driving the mantle flow field.

[24] In the one other location where mantle flow velocity has been inferred, density heterogeneity appears to be the dominant force driving mantle flow. Silver and Holt [2002] found that the subasthenospheric mantle flow velocity beneath western North America is directed eastward at $\sim 5.5 \mathrm{~cm} / \mathrm{yr}$ in a hot spot frame. While inconsistent with the kinematic return flow models noted above (which also predict southward flow beneath western North America), both subduction- and tomography-based models of density heterogeneity predict a flow field that is compatible with this result. The dominant source of this heterogeneity is the subduction of the former Farallon plate, which is prominent in both types of density fields.

[25] In contrast, for the north Atlantic these two types of density models predict different flow directions. The subduction-based density model predicts westward flow beneath Iceland, a region which, as with western flow beneath North America, is dominated by the sinking of the Farallon slab [Steinberger, 2000]. Tomography-based models predict more northward flow, because of the added influence of the large low-velocity region in the lower mantle beneath southern Africa (B. Steinberger, personal communication, 2002). This more northward mantle flow is consistent with the modified APM model of Figure 8 . It is also consistent with the hypothesis that the "African superplume" has a significant influence on mantle flow as far north as the northern Atlantic [Lithgow-Bertelloni and Silver, 1998].

\section{Conclusions}

[26] New shear wave splitting observations constrain the nature and causative mechanisms of anisotropy of the upper mantle beneath Iceland. This work constitutes the most comprehensive examination to date of anisotropy in an oceanic plume environment. While we see a systematic east-west pattern of splitting across Iceland, the observations are not easily related to simple models for the flow field expected for a mantle plume nor to any other single mechanism expected in this plume-ridge environment.

[27] The splitting observations can be matched if the dominant contribution to anisotropy is the shear induced by the absolute motion of the North American and Eurasian plates relative to a north-northwestward subasthenospheric mantle flow beneath the North Atlantic at a horizontal velocity of $3 \mathrm{~cm} / \mathrm{yr}$. We are unable to answer the question of why there is not a stronger signature of mantle flow diverging from the Iceland plume. At the same time, we acknowledge that there are more complicated hybrid models, involving two or more processes, including plumedriven flow, which we have not examined in detail. One of the virtues of the hypothesis that the splitting observations in Iceland arise from the vector difference between absolute plate motion and subasthenospheric mantle flow is that this idea is testable by observations that can be made in other areas of the north Atlantic. If the splitting parameters on the North American and Eurasian plate sides of the northern Mid-Atlantic Ridge are similar to those seen in western and eastern Iceland, respectively, then our proposed explanation for the Iceland observations is significantly strengthened. If, to the contrary, new observations reveal a different pattern for the north Atlantic upper mantle distant from Iceland, then additional explanations particular to hot spot proximity should be sought for the data of this paper.

[28] Acknowledgments. We thank Cecily Wolfe for the provision of software and for encouragement and constructive advice. We are also grateful to a number of individuals for assistance with ICEMELT field operations, including Adriana and Randy Kuehnel, Bjorn Bjarnason, Bryndís Brandsdóttir, Haukur Brynjólfsson, Kristinn Egilsson, Gunnar Gudmundsson, Eythór Hannesson, Tryggvi Hardarson, Lárus Helgason, Bogi Ingimundarson, Haraldur Jónsson, Einar Kjartansson, Pálmi Sigurdsson, Ragnar Thrudmarsson, and the staff of the National Electric Company of Iceland (Landsvirkjun). We further thank Thorsten Becker, Carolina Lithgow-Bertelloni, Neil Ribe, and Bernhard Steinberger for stimulating discussions on the geodynamic implications of our observations, and Ed Garnero and Martha Savage for constructive reviews. This work was supported by the National Science Foundation under grants EAR9316137, OCE-9402991, and EAR-9707193.

\section{References}

Ben Ismaïl, W., and D. Mainprice, An olivine fabric database: An overview of upper mantle fabrics and seismic anisotropy, Tectonophysics, 296, $145-157,1998$.

Bjarnason, I. T., How thick is the lithosphere in Iceland? How large is the velocity inversion in the asthenosphere and what does it mean? (abstract), Eos Trans. $A G U$, 80(46), Fall Meet. Suppl., F645, 1999.

Bjarnason, I. T., W. Menke, Ó. G. Flóvenz, and D. Caress, Tomographic image of the Mid-Atlantic plate boundary in southwestern Iceland, J. Geophys. Res., 98, 6607-6622, 1993.

Bjarnason, I. T., C. J. Wolfe, S. C. Solomon, and G. Gudmundson, Initial results from the ICEMELT experiment: Body-wave delay times and shear-wave splitting across Iceland, Geophys. Res. Lett., 23, 459-462, 1996. (Correction, Geophys. Res. Lett., 23, 903, 1996.)

Blackman, D. K., and J.-M. Kendall, Sensitivity of teleseismic body waves to mineral texture and melt in the mantle beneath a mid-ocean ridge, Philos. Trans. R. Soc. London, Ser. A, 355, 217-231, 1997.

Blackman, D. K., J.-M. Kendall, P. R. Dawson, H.-R. Wenk, D. Boyce, and J. Phipps Morgan, Teleseismic imaging of subaxial flow at mid-ocean ridges: Traveltime effects of anisotropic mineral texture in the mantle, Geophys. J. Int., 127, 415-426, 1996.

Chase, C. G., Asthenospheric counterflow: A kinematic model, Geophys. J. R. Astron. Soc., 56, 1-18, 1979.

Christensen, N. I., The magnitude, symmetry and origin of upper mantle anisotropy based on fabric analyses of ultramafic tectonites, Geophys. J. R. Astron. Soc., 76, 89-111, 1984. 
Darbyshire, F. A., I. T. Bjarnason, R. S. White, and Ó. G. Flóvenz, Crustal structure above the Iceland mantle plume imaged by the ICEMELT refraction profile, Geophys. J. Int., 135, 1131-1149, 1998.

Evans, J. R., and I. S. Sacks, Deep structure of the Iceland plateau, J. Geophys. Res., 84, 6859-6866, 1979.

Francis, T. J. G., Generation of seismic anisotropy in the upper mantle along the mid-oceanic ridges, Nature, 221, 162-165, 1969.

Gripp, A. G., and R. G. Gordon, Current plate velocities relative to the hotspots incorporating the NUVEL-1 global plate motion model, Geophys. Res. Lett., 17, 1109-1112, 1990.

Hager, B. H., and R. W. Clayton, Constraints on the structure of mantle convection using seismic observations, flow models, and the geoid, in Mantle Convection: Plate Tectonics and Global Dynamics, edited by W. R. Peltier, pp. 657-763, Gordon and Breach, New York, 1989.

Hager, B. H., and R. J. O'Connell, Kinematic models of large-scale flow in the Earth's mantle, J. Geophys. Res., 84, 1031-1048, 1979.

Ito, G., J. Lin, and C. W. Gable, Dynamics of mantle flow and melting at a ridge-centered hotspot: Iceland and the Mid-Atlantic Ridge, Earth Planet. Sci. Lett., 144, 53-74, 1996.

Ito, G., Y. Shen, G. Hirth, and C. J. Wolfe, Mantle flow, melting, and dehydration of the Iceland mantle plume, Earth Planet. Sci. Lett., 165, $81-96,1999$.

Kendall, J.-M., Teleseismic arrivals at a mid-ocean ridge: Effects of mantle melt and anisotropy, Geophys. Res. Lett., 21, 301-304, 1994.

Kuo, B.-Y., D. W. Forsyth, and M. Wysession, Lateral heterogeneity and azimuthal anisotropy in the North Atlantic determined from $S S-S$ differential travel times, J. Geophys. Res., 92, 6421-6436, 1987.

Lithgow-Bertelloni, C., and M. A. Richards, The dynamics of Cenozoic and Mesozoic plate motions, Rev. Geophys., 36, 27-78, 1998.

Lithgow-Bertelloni, C., and P. G. Silver, Dynamic topography, plate driving forces and the African superswell, Nature, 395, 269-272, 1998.

Menke, W., B. Bransdottir, S. Jokobsdottir, and R. Stefansson, Seismic anisotropy in the crust at the mid-Atlantic plate boundary in south-west Iceland, Geophys. J. Int., 119, 783-790, 1993.

Menke, W., M. West, B. Bransdóttir, and D. Sparks, Compressional and shear velocity structure of the lithosphere in northern Iceland, Bull. Seismol. Soc. Am., 88, 1561-1571, 1998.

Montagner, J.-P., and T. Tanimoto, Global anisotropy in the upper mantle inferred from the regionalization of phase velocities, J. Geophys. Res., 95, 4797-4819, 1990.

Montagner, J.-P., and T. Tanimoto, Global upper mantle tomography of seismic velocities and anisotropies, J. Geophys. Res., 96, 20,33720,351, 1991 .

Nishimura, C. E., and D. W. Forsyth, Rayleigh wave phase velocities in the Pacific with implications for azimuthal anisotropy and lateral heterogeneities, Geophys. J., 94, 479-501, 1988.

Óskarsson, N., S. Steinthórsson, and G. E. Sigvaldason, Iceland geochemical anomaly: Origin, volcanotectonics, chemical fractionation and isotope evolution of the crust, J. Geophys. Res., 90, 10,011-10,025, 1985.

Pálmason, G., and K. Saemundsson, Iceland in relation to the Mid-Atlantic Ridge, Annu. Rev. Earth Planet. Sci., 2, 25-50, 1974.

Parmentier, E. M., and J. E. Oliver, A study of shallow mantle flow due to the accretion and subduction of lithospheric plates, Geophys. J. R. Astron. Soc., 57, 1-22, 1979.

Raitt, R. W., G. G. Shor, T. J. G. Francis, and G. B. Morris, Anisotropy of the Pacific upper mantle, J. Geophys. Res., 74, 3095-3109, 1969.

Ribe, N. M., U. R. Christensen, and J. Theissing, The dynamics of plumeridge interaction, 1, Ridge-centered plumes, Earth Planet. Sci. Lett., 134, $155-168,1995$.

Ricard, Y., M. Richards, C. Lithgow-Bertelloni, and Y. Le Stunff, A geodynamic model of mantle density heterogeneity, J. Geophys. Res., 98, 21,895-21,909, 1993.

Rümpker, G., and T. Ryberg, New "Fresnel-zone” estimates for shear-wave splitting observations from finite-difference modeling, Geophys. Res. Lett., 27, 2005-2008, 2000.

Rümpker, G., and P. G. Silver, Apparent shear-wave splitting parameters in the presence of vertically-varying anisotropy, Geophys J. Int., 135, 790800, 1998.

Rümpker, G., and P. G. Silver, Calculating splitting parameters for plumetype anisotropic structures of the upper mantle, Geophys. J. Int., 143, 507-520, 2000.

Savage, M. K., Seismic anisotropy and mantle deformation: What have we learned from shear wave splitting?, Rev. Geophys., 37, 65-106, 1999.

Savage, M. K., and A. F. Sheehan, Seismic anisotropy and mantle flow from the Great Basin to the Great Plains, western United States, J. Geophys. Res., 105, 13,715-13,734, 2000.

Schilling, J.-G., Iceland mantle plume: Geochemical study of Reykjanes Ridge, Nature, 242, 565-571, 1973.
Schilling, J.-G., Fluxes and excess temperatures of mantle plumes inferred from their interaction with migrating mid-ocean ridges, Nature, 352, 397-403, 1991 .

Sheehan, A. F., and S. C. Solomon, Joint inversion of shear wave travel time residuals and geoid and depth anomalies for long-wavelength variations in upper mantle temperature and composition along the Mid-Atlantic Ridge, J. Geophys. Res., 96, 19,821-20,009, 1991.

Shen, Y., S. C. Solomon, I. T. Bjarnason, and G. M. Purdy, Hot mantle transition zone beneath Iceland and the adjacent Mid-Atlantic Ridge inferred from $P$-to- $S$ conversions at the $410-$ and $660-\mathrm{km}$ discontinuities, Geophys. Res. Lett., 23, 3527-3530, 1996.

Shen, Y., S. C. Solomon, I. T. Bjarnason, and C. J. Wolfe, Seismic evidence for a lower-mantle origin of the Iceland plume, Nature, 395, 62-65, 1998.

Shen, Y., S. C. Solomon, I. Th. Bjarnason, G. Nolet, W. J. Morgan, R. M. Allen, K. Vogfjörd, S. Jakobsdóttir, R. Stefánsson, B. R. Julian, and G. R. Foulger, Seismic evidence for a tilted mantle plume and north-south mantle flow beneath Iceland, Earth Planet. Sci. Lett., 197, 261-272, 2002.

Silveira, G., E. Stutzmann, D.-A. Griot, J.-P. Montagner, and L. Mendes Victor, Anisotropic tomography of the Atlantic Ocean from Rayleigh surface waves, Phys. Earth Planet. Inter., 106, 257-273, 1998.

Silver, P. G., Seismic anisotropy beneath the continents: Probing the depths of geology, Annu. Rev. Earth Planet. Sci., 24, 385-432, 1996.

Silver, P. G., and W. W. Chan, Implications for continental structure and evolution from seismic anisotropy, Nature, 335, 34-39, 1988.

Silver, P. G., and W. W. Chan, Shear-wave splitting and subcontinental mantle deformation, J. Geophys. Res., 96, 16,429-16,454, 1991.

Silver, P. G., and W. E. Holt, The mantle flow field beneath western North America, Science, 295, 1054-1057, 2002.

Silver, P. G., and M. K. Savage, The interpretation of shear-wave splitting parameters in the presence of two anisotropic layers, Geophys. J. Int., 119, 949-963, 1994.

Sleep, N. H., Hotspots and mantle plumes: Some phenomenology, J. Geophys. Res., 95, 6715-6736, 1990.

Staples, R. K., R. S. White, B. Brandsdóttir, W. Menke, P. K. H. Maguire, and J. H. McBride, Färoe-Iceland Ridge Experiment, 1, Crustal structure of northeastern Iceland, J. Geophys. Res., 102, 7849-7866, 1997.

Steinberger, B., Slabs in the lower mantle-Results of dynamic modeling compared with tomographic images and the geoid, Phys. Earth Planet. Inter. 118, 241-257, 2000.

Vinnik, L. P., V. Farra, and B. Romanowicz, Azimuthal anisotropy in the Earth from observations of $S K S$ at GEOSCOPE and NARS broadband stations, Bull. Seismol. Soc. Am., 79, 1542-1558, 1989.

Vogt, P. R., Asthenosphere motion recorded by the ocean floor south of Iceland, Earth Planet. Sci. Lett., 13, 153-160, 1971.

White, R. S., J. W. Bown, and J. R. Smallwood, The temperature of the Iceland plume and origin of outward propagating $\mathrm{V}$-shaped ridges, J. Geol. Soc. London, 152, 1039-1045, 1995.

Wilcock, W. S. D., S. C. Webb, and I. T. Bjarnason, The effect of local wind on seismic noise near $1 \mathrm{~Hz}$ at the MELT site and in Iceland, Bull. Seismol. Soc. Am., 89, 1543-1557, 1999.

Wolfe, C. J., and P. G. Silver, Seismic anisotropy of oceanic upper mantle: Shear wave splitting methodologies and observations, J. Geophys. Res., 103, 749-771, 1998. (Correction, J. Geophys. Res., 103, 2791, 1998.)

Wolfe, C. J., and S. C. Solomon, Shear-wave splitting and implications for mantle flow beneath the MELT region of the East Pacific Rise, Science, 280, 1230-1232, 1998 .

Wolfe, C. J., I. T. Bjarnason, J. C. VanDecar, and S. C. Solomon, Seismic structure of the Iceland mantle plume, Nature, 385, 245-247, 1997.

Woodward, R. L., and G. Masters, Global upper mantle structure for longperiod differential travel times, J. Geophys. Res., 96, 6351-6377, 1991.

Yang, X., and K. M. Fischer, Constraints on North Atlantic upper mantle anisotropy from $S$ and $S S$ phases, Geophys. Res. Lett., 21, 309-312, 1994.

Zhang, S., and S. Karato, Lattice preferred orientation of olivine aggregates deformed in simple shear, Nature, 375, 774-777, 1995.

I. T. Bjarnason, Science Institute, University of Iceland, Hofsvallagata 53, Reykjavík IS107, Iceland. (ingib@raunvis.hi.is)

G. Rümpker, Seismische Tiefensondierung, GeoForschungsZentrum Potsdam, Telegrafenberg, D-14473 Potsdam, Germany. (rumpker@gfzpotsdam.de)

P. G. Silver and S. C. Solomon, Department of Terrestrial Magnetism, 5241 Broad Branch Road, N. W., Washington, D. C. 20015, USA. (silver@dtm.ciw.edu; scs@dtm.ciw.edu) 